\title{
Effects of Indirect Experience of Forest Healing Factors on Stress Reduction, Self-Esteem and Social Connectedness Improvements in the Elderly Participating in Horticultural Activities Program
}

\author{
Gue Hong Park', Chang Seob Shin ${ }^{2}$, and Yang Soon Hahn ${ }^{3}$ \\ ${ }^{1}$ Graduate Department of Forest Therapy, Chungbuk National University, Cheongju 28644, Korea \\ ${ }^{2}$ Department of Forest Science, Chungbuk National University, Cheongju 28644, Korea \\ ${ }^{3}$ Department of Parks and Greenery, Gangnam-gu District Office, Seoul 06090, Korea
}

\begin{abstract}
The purpose of this study was to investigate the effect of indirect experience of forest healing factors on stress reduction and increased self-esteem and social connectedness in group-based horticultural activities. The subjects of this study were 24 elderly people aged from 60 to 77 years old. The group of 12 subjects acted as a control and participated in only gardening activities, while the other group of 12 subjects was the experimental group and participated in both forest healing session and gardening activities. In forest healing session, subjects in the experimental group watched 15-minute videos consisting of forest landscapes and sounds of water and birds in an indoor lecture hall. The program was conducted once a week for a total of 14 sessions from April to July 2017. As the result of this study, the cortisol levels, which was significantly reduced $(p=.001)$ from $3.24 \mathrm{ng} / \mathrm{ml}$ to $2.19 \mathrm{ng} / \mathrm{ml}$ in the experimental group, proved that stress levels were decreased after the program. The self-esteem of the experimental group and control groups were both significantly increased ( $p=.001$ and $p=.036)$. Also the social connectedness of the experimental group and control groups were both significantly increased after the program $(p=.001$ and $p=.018$ ). However, verification of differences between two groups showed that the differences in social connectedness in the experimental group before and after the program was significant at the $p$-value .05 level. Group-based gardening activities are effective in building better mental health, such as increased self-esteem and social connectedness in the elderly but applying forest healing programs with auditory and visual factors to conventional horticultural activities programs could enhance the effect of mental and physical health promotion in the elderly.
\end{abstract}

Keywords: auditory factor, cortisol, gardening activity, visual factor

\section{Introduction}

The medical and industrial development today has improved both quantity and quality of life for humans, and at the same time the elderly population is rapidly increasing as a global trend due to the extension of the average lifespan. This extension of the average lifespan indicates extension of senescence, and the increase in the prevalence

The work was conducted during the research year of Chungbuk National University in 2016.

Received: July 30, 2018, Revised: August 4, 2018, Accepted: August 21, 2018

First author: Gue Hong Park, E-mail: hoee21@hanmail.net, ORCID: 0000-0002-3061-018X

*Corresponding author: Chang Seob Shin, E-mail: sinna@chungbuk.ac.kr, ORCID: 0000-0002-6298-1487 
and duration of chronic degenerative diseases and senile disorders is adding more burden to families and society. The elderly also feel emotionally anxious, resulting in financial, physical and mental discouragement, and their decreased quality of life leads to stress (Kim and Kim, 2007). Stress may increase prevalence of depressive symptoms and directly affects elderly depression (Lee et al., 2004). Therefore, it is necessary to develop and promote programs and improve policy schemes to manage stress of Korean elderly (Bae et al., 2013)

In line with that, there is a growing interest in elderly well-being as a solution to the aging problem in areas with high population density. Moreover, popular leisure activities generally link nature with well-being. It is very important to easily encounter nature in daily life, and when we think of 'nature' we usually think of forests that take up $63.2 \%$ of the Korean territory. Anyone who enters a forest can easily see, hear and feel the sounds of birds and water flowing, forest landscape, smells of forest like phytoncide, and anions. Currently in-depth studies are conducted on the therapeutic effects on human body using such diverse environmental factors of forests. This is called forest healing or forest therapy, in which many people are showing more and more interest (Jeon and Shin, 2017). In other words, forest therapy is defined as immune-strengthening and health-promoting activities, which utilize a variety of elements of the forest, including scents and scenic views, in Article 2 of the Forestry Culture and Recreation Act (Ministry of Government Legislation, 2015). More and more people visit forests as a place for rest and healing, but mountains have slopes and tougher topographic conditions than flatlands and require physical strength to climb, which is why the elderly face difficulty visiting them. As such, the elderly experience mental solitude and social alienation due to weakened ability to adapt to the environment and reduced living abilities, and thus they seek leisure and life satisfaction in a residential environment where economic feasibility, convenience and sociality can be maintained or supplemented (Kim, 2012).

Previous studies on stress reduction that can be applied to the elderly include research on the effects of each healing factor by indirectly experiencing healing factors that can be felt in forests using images, sounds, photographs and videos of the forest environment. In an experiment on college students in their 20s, it was discovered that they could feel a comfortable sensation by indirectly experiencing the forest landscapes and sounds indoors more than when they received urban stimulations, and that this indirect experience had a positive effect psychologically as well (Jeon and Shin, 2017). Ulrich et al. (1991) revealed that stress is more quickly relieved in the forest environment than urban environment when the participants looked at images of plants and trees, forests and streams while also listening to the sounds of birds, winds and flowing streams at the same time. This is in line with the brainwave analysis of subjects according to visual and auditory factors by Shin et al. (2007), which showed the result that alpha waves increased when the sound of a stream flowing is added to the image with thickly grown plants. Lee et al. (2009) discovered that forests and visual environments have a positive effect on human body, with water landscape showing the greatest effect, followed by forest landscape and urban landscape. Walking around the lake in the forest or enjoying the landscape activates parasympathetic nerve actions that appear in a steady state, while suppressing sympathetic nerve actions that appear in a stressed state. This lowers the cortisol level in saliva that is a stress hormone, thereby bringing physiological stability (Song et al., 2015). Moreover, Park (2003) claimed that sound sources of nature reduce the general stress levels of elementary school students. Even when the natural factors are brought indoors, they make the human body feel stability or have excellent effect on stress reduction, thus bringing psychologically positive effects. Second, there are studies on improvement of self-esteem that affects stress, which stated that the meditation program with sounds of nature is effective in improving self-esteem of high school students (Ha, 2011), and indirectly seeing forest images significantly increased self-esteem of female members of reformatory that cannot easily encounter nature (Woo, 2016).

Group horticultural therapy, which is recently receiving attention, can be implemented on everyone, but the 
benefits of group therapy for the elderly are recently reported as a social resource (Krause, 1987). Human relations are built within such group activities, and these relations may be closely related to the improvement of social connectedness that increases the quality of life for the elderly. There are many healing programs, but integrative therapy such as forest healing and horticultural therapy (Park et al., 2015) or effect of music on horticultural therapy (Kim and Lee, 2001) refers to the application of two or more therapy programs to the same subject. Different programs can be operated in the same session, or separated into other sessions. Therapy programs are integrated because the different programs complement one another, and produce better effects than operating just one (Choi and Koh, 2014). As such, the effect of indirect experience of forest healing factors turned out to be positive, and there can be a synergy when programs are integrated such as horticultural or music therapy. However, research that applied this to the elderly is still insufficient. Thus, this study applies the forest sound, which is a forest healing factor, to the group horticultural activities program carried out in an urban forest that is convenient and accessible for the elderly, and analyze its effects on stress reduction and improvement of self-esteem and social connectedness that are necessary for improving the quality of elderly life.

\section{Methods}

\section{Subjects}

The subjects are the elderly aged 60-77 living in G-gu, Seoul who have no trouble communicating and tending a garden. They were recruited by the G-gu, Department of Parks and Greenery on the website, and the subjects were provided with sufficient explanation about the experiment when they applied. The research consent form and derived materials test consent form were received based on research ethics, and for cortisol analysis on April 6, the subjects that agreed with saliva collection were told to visit at 10 a.m. on the 13th. Fourteen subjects who actually visited were included in the experimental group. Others who did not agree with saliva collection were told to visit at 10:20 a.m. on the 13th, and 15 subjects who visited then were included in the control group, naturally dividing the subjects into two groups for the experiment. At first, 29 subjects participated in the experiment, but total 24 subjects ( 9 male and 15 female subjects) participated until the last session, who were divided into 12 in the experimental group ( 4 male and 8 female subjects) and 12 in the control group (5 male and 7 female subjects) for statistical analysis.

\section{Methods}

Yangjaecheon is an urban forest with an environment that is just as good as any other forests, and offers a program in which men and women of all ages can participate. Using this program, this experiment was conducted in total 14 sessions, once a week from April 13 to July 20, 2017, and the program (Table 1) was carried out from 10 a.m. to 11:40 a.m.

Twelve subjects in the experimental group were to watch 15-minute videos consisting of forest landscapes and sounds (water + birds) in an indoor lecture hall from 10 a.m. before the group horticultural program, while 12 subjects in the control group only participated in the group horticultural program from 10:20 a.m. without watching the 15-minute videos. The group horticultural program (Table 1) consists of natural ecology learning and gardening at the urban park of Yangjaecheon in G-gu, carried out as a Senior Eco program certified as an educational program of the Ministry of Environment based on the principle of joint cultivation, harvest and distribution. The garden is where gardening has been done for a few years after reclaiming a piece of land behind the visitors' center. In the research, one person in charge of the elderly at Yangjaecheon and two forest interpreters participated as assistances. The horticultural program was carried out 
Table 1. Contents of forest healing programs

\begin{tabular}{|c|c|c|}
\hline $\begin{array}{l}\text { Session } \\
\text { (Day) }\end{array}$ & Time & Experimental group \\
\hline $\begin{array}{c}0 \\
(4 / 6)\end{array}$ & 10:00-11:40 & Orientation and visiting a garden \\
\hline \multirow[t]{2}{*}{$\begin{array}{c}1 \\
(4 / 13)\end{array}$} & 10:00-10:15 & $\begin{array}{l}\text { Watching Minjujisan Mtn. video } \\
\text { - (water+bird) sound + forest landscape }\end{array}$ \\
\hline & $10: 20-11: 40$ & Planting green vegetables $\&$ fruit vegetables $\cdot$ Planting potatoes \\
\hline \multirow[t]{2}{*}{$\begin{array}{c}2 \\
(4 / 20)\end{array}$} & 10:00-10:15 & $\begin{array}{l}\text { Watching Bojeoksan Mtn. video } \\
\text { - bird sound + forest landscape }\end{array}$ \\
\hline & 10:20-11:40 & Sprouts growing observation $\cdot$ Planting seedlings $\cdot$ Wetland exploration in Hakyeoul \\
\hline \multirow[t]{2}{*}{$\begin{array}{c}3 \\
(4 / 27)\end{array}$} & $10: 00-10: 15$ & $\begin{array}{l}\text { Watching Gwanaksan Mtn. video } \\
\text { - water sound + forest landscape }\end{array}$ \\
\hline & $10: 20-11: 40$ & Plant growth observation $\cdot$ Drawing weeds $\cdot$ Pick my own tree \\
\hline \multirow[t]{2}{*}{$\begin{array}{c}4 \\
(5 / 11)\end{array}$} & 10:00-10:15 & $\begin{array}{c}\text { Watching Jirisan Mtn. video } \\
\text { - (water + bird) sound + forest landscape }\end{array}$ \\
\hline & $10: 20-11: 40$ & Drawing leaf vegetables $\cdot$ Making eco-friendly bags \\
\hline \multirow[t]{2}{*}{$\begin{array}{c}5 \\
(5 / 18)\end{array}$} & 10:00-10:15 & $\begin{array}{l}\text { Watching Sobaeksan Mtn. video } \\
\text { - water sound + forest landscape }\end{array}$ \\
\hline & 10:20-11:40 & Supporting tomato, pepper, and eggplant plants $\cdot$ Drawing leaf vegetables \\
\hline \multirow{2}{*}{$\begin{array}{c}6 \\
(5 / 25)\end{array}$} & 10:00-10:15 & Watching Minjujisan Mtn. video \\
\hline & 10:20-11:40 & Drawing weeds $\cdot$ Harvesting leaf vegetables $\cdot$ Finding Irises in wetlands \\
\hline \multirow{2}{*}{$\begin{array}{c}7 \\
(6 / 1)\end{array}$} & 10:00-10:15 & Watching Bojeoksan Mtn. video \\
\hline & $10: 20-11: 40$ & Harvesting vegetables $\cdot$ Learning about flowers that bloom in June \\
\hline \multirow{2}{*}{$\begin{array}{c}8 \\
(6 / 8)\end{array}$} & 10:00-10:15 & Watching Gwanaksan Mtn. video \\
\hline & $10: 20-11: 40$ & Catching insects $\cdot$ Learning about plant growth and requirements \\
\hline \multirow{2}{*}{$\begin{array}{c}9 \\
(6 / 15)\end{array}$} & 10:00-10:15 & Watching Jirisan Mtn. video \\
\hline & $10: 20-11: 40$ & Hilling up potatoes $\cdot$ Harvesting vegetables \\
\hline \multirow{2}{*}{$\begin{array}{c}10 \\
(6 / 22)\end{array}$} & 10:00-10:15 & - \\
\hline & $10: 20-11: 40$ & Harvesting vegetables $\cdot$ Coloring flowers images \\
\hline \multirow{2}{*}{$\begin{array}{c}11 \\
(6 / 29) \\
\end{array}$} & 10:00-10:15 & Watching Sobaeksan Mtn. video \\
\hline & $10: 20-11: 40$ & Harvesting potatoes $\cdot$ Harvesting tomatoes, peppers, and eggplants \\
\hline \multirow{2}{*}{$\begin{array}{c}12 \\
(7 / 6)\end{array}$} & 10:00-10:15 & Watching Minjujisan Mtn. video \\
\hline & $10: 20-11: 40$ & Harvesting tomatoes, chives and leaf vegetables $\cdot$ Making folding fans \\
\hline \multirow{2}{*}{$\begin{array}{c}13 \\
(7 / 13)\end{array}$} & 10:00-10:15 & Watching Bojeoksan Mtn. video \\
\hline & 10:20-11:40 & Harvesting tomatoes, peppers, and eggplants $\cdot$ Finding cattails and playing water drops in wetlands \\
\hline \multirow{2}{*}{$\begin{array}{c}14 \\
(7 / 20)\end{array}$} & 10:00-10:15 & Watching Jirisan Mtn. video \\
\hline & 10:20-11:40 & Vegetable fields clean up \\
\hline
\end{tabular}

in the indoor lecture hall and outdoor garden, and both groups conducted pretest and posttest. A survey was conducted on April 6 before the program for the pretest, and another survey on July 20 after the program for the posttest. The cortisol test to measure the stress level was conducted only on the experimental group that watched the 15-minute videos to minimize their hostility and discomfort after obtaining the consent forms to collect saliva cortisol and test derived materials before April 6 and after July 20. 
Kim (2014) claimed that using various sounds collected by the experimenter in various forests increases accuracy of the experiment. This experiment used 15-minute videos of forest images + forest sounds (valley stream + birds) directly filmed with a 2016 model of Galaxy Note4 by climbing the mountains in each region such as Minjujisan the Forest of Healing (Chungbuk), Cheongsando (Slow City), Bojeoksan mountain (Jeonnam), Jirisan mountain (Gyeongnam), Sobaeksan mountain (Gyeongbuk), and Gwanaksan mountain (Seoul), using the forest from April to June that displays the season of the experiment. The videos were presented in the order of month and were regularly repeated.

\section{Test tools and analysis methods}

\section{Measurement tools and test methods}

The saliva cortisol was analyzed to determine the effect on elderly stress reduction, and the self-esteem scale and social connectedness scale were used to analyze the changes in mental state. Saliva was collected in the same time zone.

\section{- Saliva cortisol test}

Cortisol, the typical stress hormone discharged when externally stressed, is widely used for stress level testing, which increases when our bodies are stressed. It could only be extracted from blood or urine in the past, but recently it can also be extracted from saliva (Park, 2010). Saliva was collected at 10:20 a.m. that is 10 minutes after the subjects rinsed their mouths with water after sufficient explanation on April 6, and at 10:20 a.m. after watching the video on July 20. They put a cotton ball under their tongues and took it out after 2 minutes when it was sufficiently soaked with saliva, which was then put into the inner tube and then the outer tube, and frozen in an icebox. The cotton balls were delivered to a specialized analysis agency in frozen state, and analyzed in the ELISA Reader (BioTek, VT, USA) using Human Cortisol ELISA Kit (DRG, NJ, USA). One out of the 12 subjects in the experimental group did not participate in the posttest sample collection, and another had foreign substances on the sample. Thus, samples of total 10 subjects were analyzed.

\section{- Self-esteem scale}

To measure self-esteem, we used a scale developed by Rosenberg (1965) and adapted by Jeon (1974). This scale is rated on a 4-point Likert scale with total 10 items (5 positive and 5 negative), with its sub-factors consisting of self-positivity and self-worth. At the point of development, the reliability (Cronbach's $\alpha$ ) was .85 and in the study by $\operatorname{Im}(2014)$ the reliability (Cronbach's $\alpha$ ) was .83. In this study, the reliability (Cronbach's $\alpha$ ) was .83, which was acceptable.

\section{- Social connectedness scale}

The scale for measuring social connectedness is the Social Connectedness and the Social Assurance Scale developed by Lee and Robbins (1995), which was revised by Lee et al (2001) measuring social connectedness conceptualized as 'subjective perception about maintaining belonging and intimacy of interpersonal relations.' This study used the scale adapted by Jeon (2009) and standardized in Korea. The social connectedness scale by Jeon (2009) is a 6-point Likert scale, consisting of 20 items such as 'I feel as if I am understood by people I know, 'I can get along with my peer group,' and 'I feel isolated from the world around me.' In the study by Lee et al. (2001), the reliability (Cronbach's $\alpha$ ) was .92 and in the study by Kim (2012) the reliability (Cronbach's $\alpha$ ) was .83. In this study, the reliability (Cronbach's $\alpha$ ) was .89, which was acceptable.

\section{Data analysis}

To determine the effects of indirect experience of forest healing factors on self-esteem, social connectedness and stress 
reduction of the elderly, this study analyzed the collected data using SPSS Windows 22.0 and calculated the reliability coefficient (Cronbach's $\alpha$ ) of the tool. To verify the effects of the program, we conducted a paired t-test as well as test of normality and non-parametric test due to a small number of samples.

\section{Results and Discussion}

\section{Cortisol test result}

The pretest-posttest difference of cortisol followed normal distribution at the significance level of .05 , which was verified through the Shapiro test (statistics 0.951, significance level .679). Thus, the paired t-test was used.

As a result of the cortisol test to measure the stress level, it was significantly reduced from $3.24 \mathrm{ng} / \mathrm{ml}$ to $2.19 \mathrm{ng} / \mathrm{ml}$ after the experiment as shown in Table 2. In other words, for the elderly in the experimental group that carried out the program applying the sound video of the forest as a forest healing factor to the group horticultural program held at the urban forest, the stress level decreased significantly in July when the program ended compared to April when it began. This is consistent with the integrative therapy analysis of forest healing and horticultural therapy by Park et al. (2015) which showed that cortisol decreased more in forest healing than horticultural therapy, and cortisol in forest healing showed a statistically significant decrease in the control group experiment on forest healing participants. However, the control group did not agree to physiological measurement and thus could not be compared with the experimental group, which is why it is unclear whether the stress reduction effect is due to the horticultural program or forest healing factors. However, there was clearly an effect on stress reduction, which may be a synergy of the program that integrated both of them.

\section{Self-esteem improvement effect}

\section{Homogeneity test by group before the program}

As a result of the Shapiro-Wilk test for the pretest scores of self-esteem, the significance level $p$ was .217 in the experimental group and .05 in the control group, and violation of normality assumption in the control group is suspected at $p<.05$. Thus, the homogeneity test was performed through the non-parametric Mann Whitney test.

According to Table 3, the pretest scores of self-esteem did not have a significant difference between the experimental group ( $\mathrm{M}=30.67)$ and the control group $(\mathrm{M}=32.33)$.

Table 2. The result of cortisol changes in the experimental group

\begin{tabular}{|c|c|c|c|c|}
\hline Cortisol & $\mathrm{M}$ & SD & $\mathrm{df}$ & $p$-value \\
\hline Pre & $3.24 \mathrm{ng} / \mathrm{ml}$ & 1.13 & \multirow{2}{*}{9} & \multirow{2}{*}{$.001^{* *}$} \\
\hline Post & $2.19 \mathrm{ng} / \mathrm{ml}$ & 0.91 & & \\
\hline
\end{tabular}

Table 3. Homogeneity test of self-esteem between experimental and control group through Mann Whitney test

\begin{tabular}{lcccc}
\hline \multicolumn{1}{c}{ Self-esteem } & M & SD & Test statistic & $p$-value \\
\hline Experimental group & 30.67 & 5.21 & 59 & .45 \\
Control group & 32.33 & 3.97 & & \\
\hline
\end{tabular}

Note. Mean values represent the sum of all scores on a 4-point Likert scale. 


\section{Posttest by group}

As a result of the Shapiro-Wilk test on the difference between the self-esteem scores before and after the program, the significance level $p$ was .70 in the experimental group and .38 in the control group, with both groups following normality at $p<.05$, Thus, there was no problem in performing the paired t-test. As a result of analyzing the self-esteem improvement effect before and after the program in both groups, self-esteem increased in both groups as shown in Table 4. However, the experimental group showed a highly significant increase of self-esteem after the program from 30.67 to 34.67 at the level of $p$-value .01, while the control group showed a significant increase from 32.33 to 34.92 at the level of $p$-value .05 . This indicates that it is more effective to implement an integrative program that applies forest healing factors to the horticultural program held in the city. Self-esteem is a variable that has a significant effect on stress for the elderly, and thus the group with high self-esteem showed higher life satisfaction than the group with low self-esteem (Lee, 2017). Therefore, improving self-esteem of the elderly helps them feel satisfied with life and effectively control emotions.

\section{Social connectedness improvement effect}

\section{Homogeneity test by group before the program}

As a result of the Shapiro-Wilk test for the pretest scores of social connectedness, the significance level $p$ was .977 in the experimental group and .056 in the control group, and the control group does not satisfy normality assumption at $p<.05$. Thus, the homogeneity test was performed through the non-parametric Mann Whitney test.

According to Table 5, the pretest scores of social connectedness did not have a significant difference between the experimental group $(\mathrm{M}=84.33)$ and the control group $(\mathrm{M}=91.83)$.

\section{Posttest by group}

As a result of the Shapiro-Wilk test on the difference between the social connectedness scores before and after the program, the significance level $p$ was .10 in the experimental group and .39 in the control group, with both groups following normality at $p<.05$. Thus, there was no problem in performing the paired t-test. As a result of analyzing the social connectedness improvement effect before and after the program in both groups, social connectedness increased in

Table 4. The result of self-esteem differences between pre- and post-program

\begin{tabular}{|c|c|c|c|c|c|}
\hline Self & & M & SD & df & $p$-value \\
\hline \multirow{2}{*}{ Experimental group } & Pre & 30.67 & 5.21 & \multirow{2}{*}{11} & \multirow{2}{*}{$.001^{* *}$} \\
\hline & Post & 34.67 & 3.11 & & \\
\hline \multirow{2}{*}{ Control group } & Pre & 32.33 & 3.98 & \multirow{2}{*}{11} & \multirow{2}{*}{$.036^{*}$} \\
\hline & Post & 34.92 & 3.32 & & \\
\hline
\end{tabular}

Note. Mean values represent the sum of all scores on a 4-point Likert scale.

${ }^{*} p<.05,{ }^{* *} p<.01$ by paired t-test

Table 5. Homogeneity test of social connectedness between experimental and control group through Mann Whitney test

\begin{tabular}{lcccc}
\hline \multicolumn{1}{c}{ Self-esteem } & $\mathrm{M}$ & SD & Test statistic & $p$-value \\
\hline Experimental group & 84.33 & 11.77 & 45 & .126 \\
Control group & 91.83 & 11.99 & & \\
\hline
\end{tabular}

Note. Mean values represent the sum of all scores on a 6-point Likert scale. 
both groups as shown in Table 6. However, the experimental group showed a highly significant increase of social connectedness after the program from 84.33 to 97.75 at the level of $p$-value .01 , while the control group showed a significant increase from 91.83 to 97.67 at the level of $p$-value .05 . This indicates that it is more effective to implement an integrative program that applies forest healing factors to the group horticultural program held in the city.

This is in line with other related studies also showed that people who participated in gardening activities built a community spirit by affecting one another through intercommunion with other residents such as encountering garden neighbors, interacting and participating in activities (Kang, 2004). Moreover, satisfaction of desires and emotional intimacy in community spirit affect intercommunion activities (Jeong, 2016). According to KOSIS (2014), the elderly face difficulty in life as they grow older because they are more likely to feel lonely and alienated. Thus, for the elderly living in the city with weakened activities, it will help promote mental and physical health of the elderly by inducing them to participate in community activities through the group horticultural program using urban forests.

\section{Verification of differences in psychological variables between groups}

The results above showed that there was a significant effect on improving self-esteem and social connectedness after the program for both the experimental and control group. However, the intergroup effect was analyzed to verify the synergy of the integrative program applying forest healing factors by comparing the differences in the effects shown between the two groups.

As a result of conducting the test for homogeneity of variance of self-esteem and social connectedness, the significance levels were .14 and .31 , satisfying homogeneity of variance at $p<.05$ in the t-test. As a result, the mean change of self-esteem in the experimental group before and after the program is 4.00 as shown in Table 7 , and that of the control

Table 6. The result of social connectedness differences between pre- and post-program

\begin{tabular}{|c|c|c|c|c|c|}
\hline \multicolumn{2}{|c|}{ Social connectedness } & M & SD & $\mathrm{df}$ & $p$-value \\
\hline \multirow{2}{*}{ Experimental group } & Pre & 84.33 & 11.77 & \multirow{2}{*}{11} & \multirow{2}{*}{$.001^{* *}$} \\
\hline & Post & 97.75 & 9.79 & & \\
\hline \multirow{2}{*}{ Control group } & Pre & 91.83 & 11.99 & \multirow{2}{*}{11} & \multirow{2}{*}{$.018^{*}$} \\
\hline & Post & 97.67 & 12.64 & & \\
\hline
\end{tabular}

Note. Mean values represent the sum of all scores on a 6-point Likert scale.

${ }^{*} p<.05,{ }^{* *} p<.01$ by paired t-test

Table 7. Verification of differences between groups

\begin{tabular}{|c|c|c|c|c|c|c|c|c|c|c|c|}
\hline \multirow{3}{*}{ Variable } & \multirow{3}{*}{ Group } & \multirow{3}{*}{$\mathrm{n}$} & \multicolumn{4}{|c|}{ Difference between pre- and post- } & \multicolumn{5}{|c|}{ Effect verification } \\
\hline & & & \multicolumn{2}{|c|}{ Pre } & \multicolumn{2}{|c|}{ Post } & \multicolumn{2}{|c|}{ Post - Pre } & \multirow{2}{*}{$\mathrm{t}$} & \multirow{2}{*}{ df } & \multirow{2}{*}{$p$} \\
\hline & & & M & SD & M & SD & M & SD & & & \\
\hline \multirow{2}{*}{ Self-esteem } & Experimental & 12 & 30.67 & 5.21 & 34.67 & 3.11 & 4.00 & 2.59 & \multirow{2}{*}{1.08} & \multirow{2}{*}{22} & \multirow{2}{*}{.29} \\
\hline & Control & 12 & 32.33 & 3.98 & 34.92 & 3.32 & 2.58 & 3.75 & & & \\
\hline \multirow{2}{*}{$\begin{array}{l}\text { Social } \\
\text { connectedness }\end{array}$} & Experimental & 12 & 84.33 & 11.77 & 97.75 & 9.79 & 13.42 & 10.11 & \multirow{2}{*}{2.11} & \multirow{2}{*}{22} & \multirow{2}{*}{$.046^{*}$} \\
\hline & Control & 12 & 91.83 & 11.99 & 97.67 & 12.64 & 5.83 & 7.25 & & & \\
\hline
\end{tabular}

Note. Mean values in self esteem represent the sum of all scores on a 4-point Likert scale and mean values in social connectedness represent the sum of all scores on a 6-point Likert scale.

${ }^{*} p<.05$ by two sample t-test 
group was 2.58 , but the difference in the mean change between the two groups was 1.42 that was not statistically significant. However, the mean change of social connectedness in the experimental group before and after the program is 13.42 , and that of the control group was 5.83. The mean change between the two groups was 7.58 , which is a significant difference at the significance level of .05 .

This is because psychological relaxation from watching videos of forest landscapes and sounds for 15 minutes promoted emotional exchange of the elderly engaged in group activities in this experiment, as proved by a previous study that viewing forest landscapes for 15 minutes relaxes our bodies (Park, 2010).

\section{Conclusion}

This study aimed to determine the effects of group horticultural activities applying forest healing factors on stress reduction and improvement of self-esteem and social connectedness of the elderly. Thus, to reveal the effects of indirect experience of forest healing factors, we recorded sounds of streams and birds that have the greatest relaxation effect psychologically and physiologically, and created 15-minute videos. The subjects were divided into the experimental group that participated in the group horticultural program to which forest healing factors were added, and the control group that only participated in the group horticultural program. The results were as follows.

First, the subjects were to watch videos with forest sounds (streams + birds) with physiologically great relaxation effect to determine the stress reduction effect throughout 13 sessions, 15 minutes each. The result showed that the cortisol level decreased from average $3.24 \mathrm{ng} / \mathrm{ml}$ to average $2.19 \mathrm{ng} / \mathrm{ml}$ after the program, showing statistically significant difference. Second, the results before and after the program were compared to determine the self-esteem increasing effect of the elderly that participated in the group horticultural program. The result showed that there was a statistically significant difference in both groups, thereby proving effects. However, the experimental group that watched the forest sound videos for 15 minutes every session showed a greater statistically significant difference, indicating that the integrative program applying forest healing factors had a synergy compared to just the program. Third, the experimental group that watched the forest sound videos for 15 minutes every session also showed effect on increasing social connectedness, showing a statistically significant difference from average 84.33 to average 97.75 after the program. Fourth, there was a significant difference in social connectedness when horticultural activities were carried out after applying forest healing factors (forest sound videos) compared to the control group that did not apply forest healing factors. This is because by applying forest healing factors that generated a comfortable sensation, the elderly engaged in group activities could relieve stress and interact in a physiologically and psychologically stable state. This indicated that group horticultural programs including gardening activities are necessary, and that applying integrative programs that added forest healing factors to urban horticultural programs is more effective for promoting mental and physical health of the elderly.

Therefore, the following suggestions can be made based on the results. First, it is necessary to increase shaded rest areas and natural factors for group activities and programs carried out along urban streams. There is a forest trail for walking at the Yangjaecheon urban forest, but it is also necessary to provide leafy shades along the stream where the sounds of water flowing can be heard, and plant tall trees and bushes to use as food and resources for birds. Thus, by creating shades by planting trees and enriching natural factors such as birds or insects, we suggest creating a riverside forest for visitors to walk along the woodland path and listen to the sounds of nature. Second, integrative programs must be made by adding other factors such as listening to sounds or nature or watching forest videos that psychologically and physiologically relaxes the elderly to programs for group activities, because these integrative programs can double the effect of such community activities. This study has limitations as it failed to comparatively analyze the experimental group and control 
group in terms of cortisol analysis and does could not clearly determine the effects. There is a need for more in-depth follow-up research in analyzing cortisol that reveals stress levels, and various studies on the therapeutic effects of each forest healing factor.

\section{References}

Bae, J.I., H.H. Kim, M.K. Yang, H.J. Kim, J.H. Kim, and H.H. Lim. 2013. Stress and management strategies in Korean elderly. Crisisonomy 9(3):175-194. Retrieved from http://www.cemtp.re.kr

Choi, S.J. and Y.S. Koh. 2014. Effect of combined program of horticultural therapy and forest therapy on self-esteem, social competence, and life respect of low-income family children at community children's center. Master's thesis, Hallym University, Chuncheon, Korea.

Ha, M.Y. 2011. The Effects of meditation music program with nature sound on high school student's self-esteem. Master's thesis, Changwon University, Changwon, Korea.

Im, Y.S. 2014. Impacts of forest therapy program on the self-esteem, depression degree and life-satisfaction of senior citizens in nursing home. Master's thesis, Chungbuk University, Cheongju, Korea.

Jeon, B.J. 1974. Self-esteem: A test of its measurability. Yonsei Res. Inst. 11(1):107-130.

Jeon, J.Y. and C.S. Shin. 2017. Effects of indirect forest experience on human psychology. Korean J. Environ. Ecol. 31(4):420-427.

Jeon, M.I. 2009. Mediating effects of social connectedness on the relationships between multidimensional perfectionism and depression, subjective well-being. Master's thesis, Catholic University, Seoul, Korea.

Jeong, S.O. 2016. Graduate school of natural resources \& life sciences. Master's thesis, Cheonbuk University, Cheonju, Korea.

Kang, D.G. 2004. Understanding and quest for community. Paju, Korea: Acanet.

Kim, H.S. and B.S. Kim. 2007. The Effect of self-esteem on the relationship between the elderly stress and depression. J. Korean Gerontol. Soc. 27(1):23-37.

Kim, H.S. and E.H. Lee. 2001. A study on the effect of horticultural therapy with music. J. Korean Soc. People Plants Environ. 4(1):27-33.

Kim, I.O. 2014. The influence of auditory elements of forest on psychological and physiological response. Master's thesis, Chungbuk University, Cheongju,, Korea.

Kim, Y.R. 2012. The relationship between urban forest use and senior citizen's social bonding and QOL. Master's thesis, Chungbuk University, Cheongju, Korea.

KOSIS (Korean Statistical Information Service). 2014. Elderly person statistics: 22 difficulties experienced by the elderly. Retrieved from www.kosis.kr

Krause, N. 1987. Life stress, social support and self-esteem in an elderly population. Psychol. Aging 2(4):349-356. DOI:10.1037/0882-7974.2.4.349

Lee, J.H., W.S. Shin, P.S. Yeoun, and R.H. Yoo. 2009. The influence of forest scenes on psychophysiological responses. J. Korean For. Soc. 98(1):88-93.

Lee, P.S., Y.M. Lee, G.Y. Lim, L.I. Hwang, and E.Y. Park. 2004. The relationship of stress, social support and depression in the elderly. J. Korean Acad. Nurs. 34(3):477-484.

Lee, R.M., M. Draper, and S. Lee. 2001. Social connectedness, dysfunctional interpersonal behaviors, and psychological distress: Testing a mediator model. J. Couns. Psychol. 48(3):310-318. DOI:10.1037/0022-0167.48.3.310

Lee, R.M. and S.B. Robbins. 1995. Measuring belongingness: The social connectedness and the social assurance scales. J. Couns. Psychol. 42(2):232-241. DOI:10.1037/0022-0167.42.2.232

Lee, S.J. 2017. The effect of elderly life stress and self-esteem on satisfaction of life. J. Humanit. Soc. Sci. 8(3):1077-1091. 
Ministry of Government Legislation. 2015. Act on forest culture and recreation. Retrieved from www.moleg.go.kr

Park, B.J. 2010. Experimental approach of therapeutic effect of forest recreation activities. Doctoral dissertation, Chungnam National University, Daejeon, Korea.

Park, S.A., M.S. Jeong, and M.W. Lee. 2015. An analysis of the healing effects of forest therapy and horticultural therapy. J. Korean Inst. Landsc. Archit. 43(3):43-51.

Park, Y.S. 2003. Effects of meditation music with nature sound on primary school children's stress reduction. Master's thesis, Changwon University, Changwon, Korea.

Rosenberg, M. 1965. Society and the adolescent self-image. Princeton, NJ: Princeton University Press.

Shin, Y.G., J.H. Jeon, G.S. Jang, C. Kook, and S.W. Kim. 2007. Emotional evaluation according to the changes of visual and auditory landscape elements in residential areas. Trans. Korean Soc. Noise Vib. Eng. 17(7):611-616.

Song, C.S., J.Y. Lee, H. Ikei, T. Kawada, Y. Miyazaki, and B.J. Park. 2015. Physiological and psychological effects of walking around and viewing a lake in a forest environment. J. Korean For. Soc. 104(1):140-149.

Ulrich, R.S., R.F. Simons, B.D. Losito, E. Fiorito, M.A. Miles, and M. Zelson. 1991. Stress recovery during exposure to natural and urban environments. J. Environ. Psychol. 11(3):201-230. DOI:10.1016/S0272-4944(05)80184-7

Woo, Y.J. 2016. Influence of the forest image on mental health of reformatory facility students and academic high school students. Master's thesis, Chungbuk University, Cheongju, Korea. 